research at the 2017 AATS Annual Meeting. Deadline: January 20, 2017

Summer Intern Scholarship: Provides first- and secondyear medical students with an eight-week summer internship in an AATS member's CT surgery department. Deadline: January 13, 2017

\section{Invest in the Future}

Every day CT surgeons transform the lives of their patients around the world. Your support is essential to ensure the fu- ture of our specialty and continue advancing global innovation in CT surgery. Please make a gift to the Foundation or renew your commitment. Together, we can promote our specialty not only for the next generation of surgeons, but also the patients they serve.

For individual and corporate/organizational giving opportunities, kindly visit the Foundation's Web site at www.aatsgrahamfoundation.org or contact the Development Office at 978-927-8330.

\section{The Western Thoracic Surgical Association}

\section{The WTSA 2016 Annual Meeting in Review}

The 42nd Annual Meeting of the Western Thoracic Surgical Association was held at the Hilton Waikoloa Village in Waikoloa, Hawaii, June 22-25, 2016. The meeting included oral presentation of 20 original papers, panel discussions, a postgraduate course, and 39 other papers presented during concurrent forums in the disciplines of adult cardiac, general thoracic, and congenital heart disease. The Annual Meeting attracted more than 260 physicians and allied health professionals and provided an outstanding educational program with ample opportunities for open discussion, scientific debate, and the collegiality characteristic of the WTSA Annual Meeting.

Educational highlights of the program included the Presidential Address, delivered by John D. Mitchell and entitled "Tuberculosis, History, and the Arts." In addition, a Controversies Debate, which asked, "Concurrent Surgery: Efficient or Unethical?," was moderated by Richard I. Whyte and featured talks by Robert J. Cerfolio and Sean C. Grondin.

A Breakfast Session, "Public Reporting of Surgeon-Specific Data: Friend or Foe?," was moderated by Susan MoffattBruce, with presentations by Joseph C. Cleveland, Jr, Felix G. Fernandez, and John E. Mayer. This was followed by the Postgraduate Course, titled "War Surgery in Iraq and Afghanistan" and sponsored by White Memorial Medical Center and Foundation, Lyman A. Brewer III Fund, as well as by a donation from Thomas J. Fogarty; this course featured Cameron D. Wright, Associate Chief of the Division of Thoracic Surgery \& Associate Program Director at Massachusetts General Hospital in Boston.

The C. Walton Lillehei Point/Counterpoint Session, entitled "Surgeons on the Heart Team: Quarterbacks or Water Boys?," was moderated by David A. Fullerton with Joseph E. Bavaria and T. Brett Reece arguing for their sides. Several awards were presented during the meeting. The David J. Dugan Distinguished Service Award was presented to
D. Craig Miller of Stanford University Medical School in California for his distinguished achievements in cardiothoracic surgery. In addition, the Donald B. Doty Educational Award was given to Nahush A. Mokadam, from the University of Washington Medical Center in Seattle, for his project on "3D Printing Technology for Cardiothoracic Resident Training in Myectomy and VSD Closure"; the Norman E. Shumway Award for the Best Paper coauthored by a WTSA member was presented to Camille L. Stewart of the University of Colorado School of Medicine in Aurora, for her presentation, "Is Re-Staging Positron Emission Tomography Required After Neoadjuvant Treatment for Esophageal Cancer?"; and the Samson Resident Prize Essay Award was given to Billie-Jean Martin of the University of Alberta in Edmonton for "Regionalized Surgical Care: An Important Lack of Association Between Distance From Surgical Center and Postoperative Outcomes in Children Undergoing Fontan Palliation."

The 2016-2017 Officers elected during the meeting include: President James I. Fann, Stanford, California; Vice President Ross M. Bremner, Phoenix, Arizona; Secretary Sean C. Grondin, Calgary, Alberta, Canada; Treasurer Joseph C. Cleveland, Jr, Aurora, Colorado; Councilor John D. Mitchell, Aurora, Colorado; Councilor-at-Large Craig J. Baker, Los Angeles, California; Councilor-at-Large Brian L. Reemtsen, Los Angeles, California; Historian Douglas E. Wood, Seattle, Washington; and Editor Richard D. Weisel, Toronto, Ontario, Canada.

Also during the 42nd Annual Meeting, 32 new members were elected to WTSA membership-24 to Active membership and 8 to Candidate membership: Ghannam A. Al-Dossari, San Francisco, California; Francisco Arabia, Los Angeles, California; Mark F. Berry, Stanford, California; Castigliano Bhamidipati, Seattle, Washington (Candidate); Marineh Bojalian, Los Angeles, California; Jack Boyd, Stanford, California; Sagar S. Damle, Lincoln, Nebraska; Sevak H. Darbinian, Mission Viejo, California; Costanzo A. Di Perna, Carmichael, California; Gansevoort H. Dunnington, Jr, St. Helena, California; Alec Eror, St. George, Utah; Matthew Forrester, Spokane, 


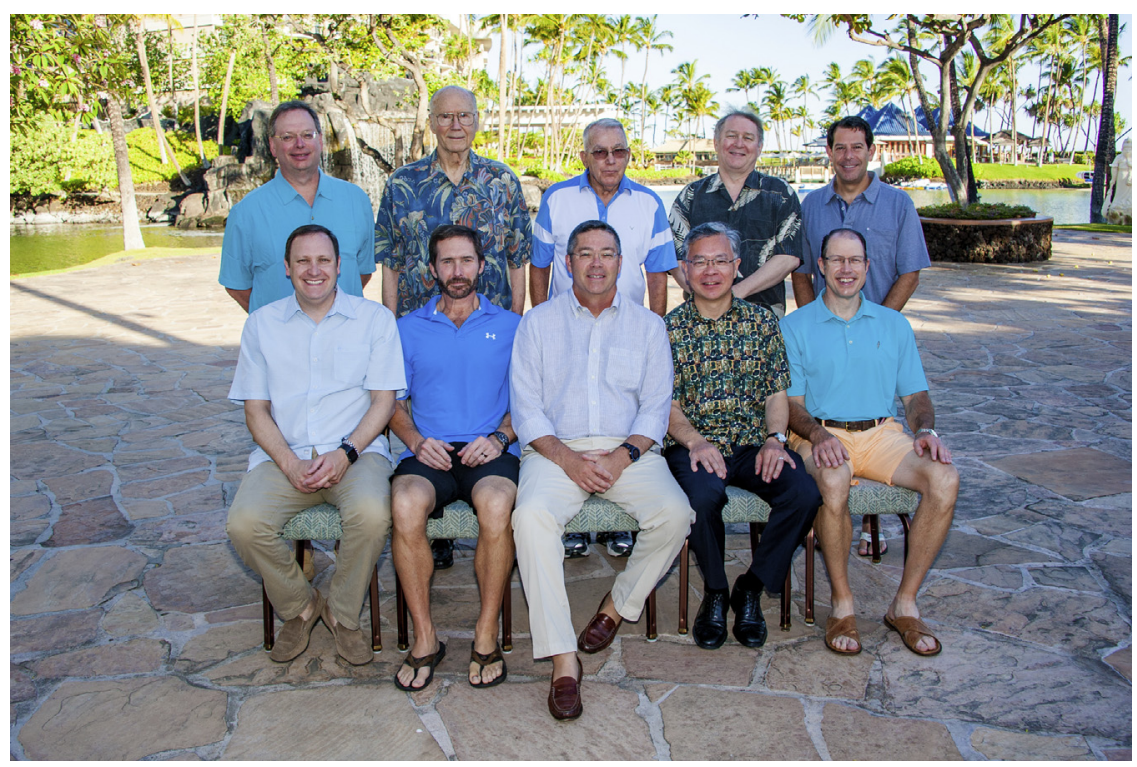

2015-2016 WTSA Council (seated, left to right) Sean C. Grondin, Michael S. Mulligan, John D. Mitchell, James I. Fann, and Joseph C. Cleveland, Jr; (standing, left to right) Anthony P. Furnary, Arthur N. Thomas, Marvin Pomerantz, Richard I. Whyte, and Craig J. Baker; (missing) Richard D. Weisel.

Washington; Eric R. Griffiths, Salt Lake City, Utah (Candidate); Richard-Tien V. Ha, Stanford, California; Amy E. Hackmann, Los Angeles, California; Katherine B. Harrington, Plano, Texas; Joshua L. Hermsen, Seattle, Washington; Daniel D. Holloway, Calgary, Alberta (Candidate); Ali Ibrahimiye, Palo Alto, California (Candidate); David Joyce, Rochester, Minnesota; Lauren C. Kane, Houston, Texas; Ganesh Kumpati, Salt Lake City, Utah; Eric J. Lehr, Seattle, Washington; Michael C. Monge, Chicago, Illinois; Daniel S. Oh, Los Angeles, California; Amit Patel, Salt Lake City, Utah; Brian B. Rezvani, Los Angeles, California (Candidate); Raina Sinha, Los Angeles, California (Candidate); Mary C. Smith, Bellingham, Washington; Jennifer L. Sullivan, Memphis, Tennessee (Candidate); Luke M. Wiggins, Los Angeles, California (Candidate); and Jeffrey J. Wu, Honolulu, Hawaii.

\section{Applications for Membership}

The WTSA is now accepting Applications for Membership online for Active as well as Candidate membership status. Visit the WTSA Web site at www.westernthoracic.org to read the complete membership eligibility requirements and to initiate an online application.

\section{Active Member}

$\$ 375.00$ annually, plus $\$ 50.00$ initiation fee

Applicant must meet all membership criteria, including but not limited to:

- Reside within or have completed a cardiothoracic residency training program within the geographic limits of the Association.
- Have been engaged in the practice of thoracic and cardiovascular surgery for at least three years following completion of postgraduate training. If a candidate completed his/her thoracic surgical residency or a one-year clinical fellowship in an institution within the geographic limits of the Association, such completion may count toward one of the three years of practice.

- Have a full and unrestricted license to practice medicine in his or her respective state or province, and have a current appointment on the surgical staff of a hospital with no reportable action pending which could adversely affect such applicant's staff privileges at any hospital.

\section{Candidate Member}

$\$ 100.00$ annually

Applicant must meet all membership criteria, including but not limited to:

- Be matched or enrolled in either a cardiothoracic surgery education program accredited by the Residency Review Committee for Thoracic Surgery under the authority of the ACGME or a program approved for cardiothoracic surgery education by the Royal College of Surgeons of Canada — or their equivalency — from within the Association's geographic limits. Individuals who have completed their education in one of the above programs but do not yet meet all of the criteria for Active membership also are eligible to apply for Candidate membership. Individuals who trained outside the Association's geographic limits who are now residing within the 